\section{Birlesik Dünya Arastırma Global Journal of Computer BD - CENTER \\ Innovasyon ve Yayıneılık Merkezi \\ Sciences: Theory and \\ Research}

Volume 11, Issue 2, (2021) 88-99

$\underline{\text { www.gjcs.eu }}$

\title{
Smart learning technology for computer programming based on research related to COVID-19
}

Ramona Markoska ${ }^{1}$, Faculty of Information and Communication Technologies, "St. Kliment Ohridski" University, Partizanska bb, MK-7000 Bitola, North Macedonia. https://orcid.org/0000-0002-4594-1248

\section{Suggested Citation:}

Markoska, R. (2021). Smart learning technology for computer programming based on research related to COVID19. Global Journal of Computer Sciences: Theory and Research. 11(2), 88-99. https://doi.org/10.18844/gjcs.v11i2.5380

Received from June 12,2021; revised from August 17,2021; accepted from October 8,2021.

Selection and peer review under responsibility of Prof. Dr. Doğan Ibrahim, Near East University, Cyprus.

${ }^{{ }^{2}} 2021$ Birlesik Dunya Yenilik Arastirma ve Yayincilik Merkezi. All rights reserved.

\begin{abstract}
The restrictions imposed by COVID-19 have significantly affected the reorganization of educational processes, including the process of computer programming learning in higher education. The work experiences in teaching programming languages in higher education have served as an idea for the development of smart learning technology, as a complement to the preexisting ecosystem for digital learning, in particular C++ programming, in higher education. This paper aims to present the realization of smart learning technology, describes its use and provides information about the level of acceptance of higher education students. The opinions and experiences of the students who used the technology, during the summer semester of 2020, were obtained through an anonymous questionnaire, prepared by the author of the paper. The results were obtained during implementation of the curriculum in advanced C++ programming in the Faculty of ICT. The results show the potential for wider application of this Smart Learning technology, especially in technical areas.
\end{abstract}

Keywords: C++; covid19; programming; smart learning, technology

\footnotetext{
1* ADDRESS FOR CORRESPONDENCE: Ramona Markoska, Faculty of ICT, "St. Kliment Ohridski" University, Partizanska bb, MK-7000 Bitola, North Macedonia E-mail address: ramona.markoska@uklo.edu.mk/ Tel.: +389-77-744-744
} 
Markoska, R. (2021). Smart learning technology for computer programming based on research related to COVID-19. Global Journal of Computer Sciences: Theory and Research. 11(2), 88-99. https://doi.org/10.18844/gjcs.v11i2.5380

\section{Introduction}

The emergence of COVID-19 is a significant immaterial factor that has marked all areas of human life worldwide, including education. This unconventional situation leads to behavioural changes of all age groups, encouraging the use of Information and Communication Technologies (ICT) -enabled solutions for communication and working needs, as an alternative to physical presence. Young people are best adapted to this new situation. Some relevant research show that in the 21st century, for most young people, technology is a significant part of their daily lives, presenting that by age 21 , today's average person spends 15,000 hours in formal education, 20,000 hours in front of a TV and 50,000 hours in front of a computer screen [1] .

In terms of the necessary educational change, this situation leads to a solution where smart learning technologies, functionally very close to young people, compensate the negative impact of COVID-19. Even before the COVID-19 crisis, many universities in the world worked on improving the strategies used to maintain support systems to enhance students' online experience in meeting their educational goals, offering comprehensive online student Imperative of each modern educational institution which enrols students in online degree programmes support [2] , to provide learning services of equal quality to those offered to campus-based students. Furthermore, the use of ICT in education, followed by conceptual advances in technical paradigms, has grown rapidly in the last 10 years. In terms of material factors relevant to education, following market changes, desktop configurations have been replaced by laptops and further by tablets and mobile phones, which are more accessible and better manageable.

Regarding the organisational aspect of ICT solutions, the preferred way of communication between devices is constantly changing. There have been major subsequent changes in the educational paradigm. The first step was the upgrade of e-learning, which was defined as computer training, towards mobile learning (m-learning), based on mobile and wireless technologies. The further changes have moved the m-learning environment to the u-learning environment (ubiquitous learning), which can be accessed in a variety of contexts and situations [3]. The u-learning environment allows students to access educational content anytime, anywhere through a variety of terminals, without restrictions on time, place, or environment [3-5] .

In practice, e-learning, m-learning, and u-learning technologies are vertically compatible and complementary at the same time, and can be used in parallel, if necessary, in a single learning environment. This concept leads to the development of a personalised learning system, equipped with multi-level services that offer a personalised scalable opportunity for education and practice [3]. It is a complete learning ecosystem in which both the student and his environment flexibly respond to constant changes through interaction and mutual improvement, thus growing into a smart learning (slearning) ecosystem [5,6]. Each s-learning environment should have a set of multiple additional smart components to implement, maintain and actively use distinctive smartness features, also known as several levels of intelligence, such as adaptation, sensing, inferring, self-learning, anticipation, selforganisation, restructuring and optimisation [5].

The term smart has been used to modify a learning environment as well as technology [7]. Every slearning process should be supported by smart learning technologies, and both of them fused together, grow into an s-learning environment. Not every smart technology is a smart learning 
technology. Learning and training support should be the primary consideration. In this context, the technology is seen as practical application of knowledge for a purpose that is of value to a group of people, including physical things, as well as things that are conceptual or abstract (such as sorting algorithms, codes, and a way of interaction through cloud-programming environments [4]. By analysing previous considerations and obtained knowledge, it can be concluded briefly that smart learning is an intelligent, tailored instruction-learning supporting system with changes in the overall smart education system, which aims to provide holistic learning using modern technologies [8]. ICT solutions used in smart learning are recognised as smart learning technology, in the most general context.

\subsection{Conceptual background}

In this paper, the main activity is the development of new technology. According to previous overviews, every smart learning technology is developed to support some pre-existing smart learning system, ensuring, and enabling the needed changes. To ensure the success of this process, it is crucial to identify the key influencing factors in order to enhance the strengths of the learning environment and to overcome and improve the weaknesses. The implemented smart learning technology presented in this paper is a functional complement to the existing smart learning ecosystem, applied for many years. The idea behind the development of smart learning technology is to regulate the transition from learning through practical physical presence to full online learning. The reason for such a change is the need to reorganise the various levels of social interaction imposed by COVID-19, including educational processes. Before presenting the functionalities of smart computer programming learning technology, a step-by-step overview of the development concept is given as follows.

\subsubsection{New opportunities that smart learning technology for computer programming offer}

In the conditions imposed by COVID-19, the most critical part of the transition to full online learning is the process of qualitative and quantitative changes in the code, which requires repetitive activities, such as code editing, modification of conditions and input variables, compiling, debugging, linking and execution. All of these activities have different roles: the main goal is to make the code error-free and what can be done in that regard, but further goals include editing and advanced manipulation of an already functioning executable code, such as monitoring the impact of input data changes, the use of standardised libraries in $\mathrm{C}++$ and creating and executing custom headers. Based on the given notes, the developed smart learning technology has the following features:

- The technology is used as an interactive book and compiler at the same time

- $\quad$ The user (student) does not need an account and login to use it

- $\quad$ The technology can be used by several students at the same time, and the changes made by each individual have no impact on the basic educational content, which remains unchanged.

- $\quad$ The technology consists of multiple sets of lessons - for examples with educational code - and each can be accessed as needed several times and at any time.

- There is an opportunity for interactive change of the basic content-code, and both can be downloaded for future local exercising, if needed. 


\subsection{Problem statement}

In the process of acquiring practical skills in computer programming, the necessary work changes in correlation with the COVID-19 recommendations, requiring full digitalisation of the procedures that took place regularly in the laboratories of the faculty. This includes developing a solution to the problem, in which programme code processing activities will take place in a smart learning environment, as a substitute for real labs, in which the activities were physical and virtual, as needed. Smart learning environments supported by smart learning technologies should not only enable learners with digital resources and interaction with learning systems in any place and at any time, but also actively provides them with the necessary, learning guidance, supportive tools or learning suggestions [9], offer scalability, self-learning, and self-training support.

The basic concept of this technology, designed in addition to the existing smart learning system, is based on many years of practical experience, and an initial version has been prepared. It is important to note that some courses and areas of education are particularly relevant to the concept of smart education, which incorporates s-learning processes and smart learning technologies' use. These include the various areas of application and use of ICT at various levels and situations, with particular emphasis on the study of programming languages and technologies. The new reality in all domains of human behaviour, conditioned by the emergence of COVID-19, strongly imposed the need to use smart learning technologies to build s-learning systems at different educational levels and subjects of education.

\subsection{Purpose of study}

This paper aims to present the realization of smart learning technology, describes its use, and provides information about the level of acceptance of higher education students. The development of smart learning technology, described in this paper, is a real response to these needs in the field of computer programming education in higher education. Furthermore, the developed smart learning technology provides the opportunity for continuous improvement of pre-established smart learning ecosystems. Existing experiences of using an existing digital ecosystem and feedback from students who have previously used similar digital technologies are used directly to develop this smart learning technology. The opinions of the students expressed in the questionnaire are taken as a precondition for future changes in the quality of the existing functionalities and possible additions with new ones.

\section{Methods}

The work methodology consists of two compatible and complementary activities. The main activity consists of conceptual design and implementation of smart learning technology presented in this paper. The secondary activity consists of receiving feedback on students' work experiences. The second activity, as usual in the development of other components of the digital learning ecosystem, involves the subsequent monitoring of feedback from several generations of students before moving on to corrections and upgrading of smart learning technology. In this context, the second activity is only an initial aid for recognising the trends of acceptance and application of smart learning technology and, in this paper, gives the directions for possible development and further application of described smart learning technology. According to the main activity, the working methodology for 
development of the smart learning technologies is based on open source solutions, tools and platforms: jdoodle (https://www.jdoodle.com/) compiler functionalities based on REST API, blogspot widgets (https://blogger.com/), JavaScript and HTML. In terms of functionalities, the computer programming smart learning technology relies on theoretical preparation, practical exercises and a process of practical testing and assessment of students' skills and abilities.

\subsection{Data collection}

According to the second activity, the initial evaluation of the concept of smart learning technology was made through an anonymous survey of students who used it during the semester, in the time interval March-June 2020. The survey was realised using Google Forms.

\subsection{Sample}

From the beginning of the semester until the end of June, 125 students were interviewed for their opinions on and experience in the following main categories:

- $\quad$ Organisational items, which refer to the comparison of physical presence with the online presence, expressed through individual factors of importance and in general.

- $\quad$ Content changes - cloud training and interactive book for learning and practical work in C++.

- $\quad$ Student's point of view about COVID-19-related changes.

\section{Results}

The results of the survey are shown in Figure 1 as summary statistics from the research conducted in Macedonian language, which is available at http://www.ramona-markoska.info/2020/05/2020covid19.html. 
Markoska, R. (2021). Smart learning technology for computer programming based on research related to COVID-19. Global Journal of Computer Sciences: Theory and Research. 11(2), 88-99. https://doi.org/10.18844/gjcs.v11i2.5380

Online lectures and cloud exercises in Advanced Programming vs classical forms in Structured programming. My personal opinion: better is

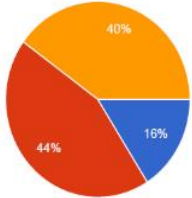

$40 \%$ Online learning

$16 \%$ Physucal presence

$44 \%$ No difference

The way of communication in COVID19 conditions, the teaching needs, satisfaction level

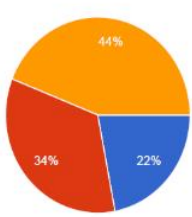

$22 \%$ Difficult, and lacked direct physical communication

$44 \%$ There is no difference - suitable e tools are available

$34 \%$ Better - because of additional activities in the direction of using e-tools

During the online activities there are problems with:

50 responses

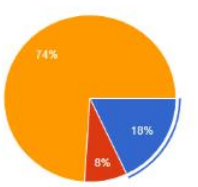

$18 \%$ unstable internet connection

$8 \%$ software platforms,

$74 \%$ satisfactory processes, no problems

The impact of organizational change related to covid 19 on the quality of education

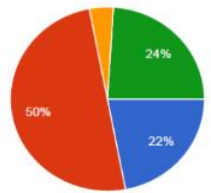

$22 \%$ reduced quality,

$4 \%$ improved quality,

$50 \%$ no difference,

$24 \%$ improvement that should be maintained even after the crisis 19

The introduced changes facilitate the way of mastering the material

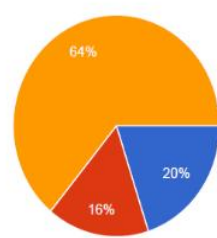

$64 \%$ Agree,

$16 \%$ Disagree

$20 \%$ No difference

A better way to practice computer programming and evaluate practical activities is

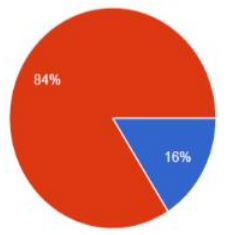

$16 \%$ faculty training and evaluation, with physical presence,

$84 \%$ online cloud training and evaluation through personal accounts
Benefits of using the interactive book $\mathrm{C}++$ (choose more)

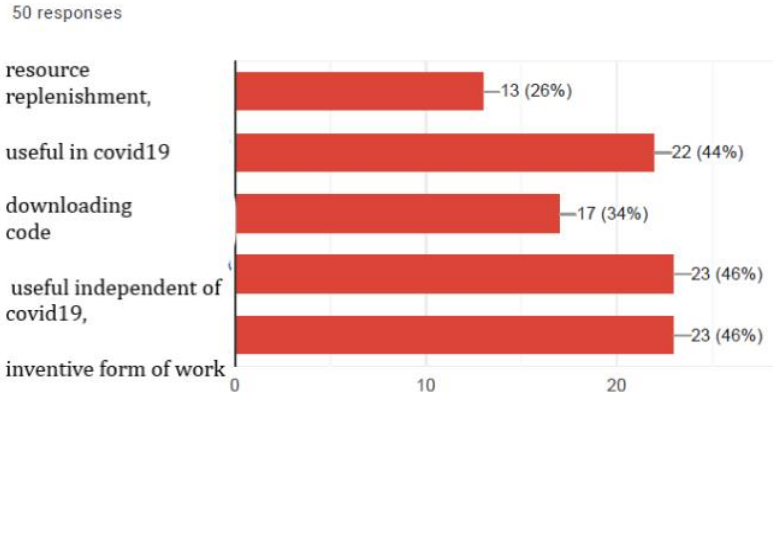

Figure 1: Survey results of the COVID-19-related research

The questionnaire was answered anonymously by $86.2 \%$ of the total number of students who attended the lectures online. A summary of the research's conclusion, based on the obtained results are as follows:

- Measurable satisfaction and acceptance of the complete transition to work via the Internet: out of all students, only $16 \%$ said they prefer physical presence, as opposed to $84 \%$ of which 
$44 \%$ did not make a difference and $40 \%$ preferred online work and $74 \%$ are satisfied with the quality of digital communications and the Internet.

- Preferences for practising computer programming over the Internet and using free access to content or personal accounts showed $84 \%$ of students, as opposed to $16 \%$ who preferred physical presence in laboratories.

- The impact of COVID-19 changes on the way of communication, the level of students' satisfaction and the overall educational needs is positively evaluated: only $22 \%$ of the students felt a decrease in quality, while $50 \%$ did not notice any changes, while $24 \%+4 \%$ thought that these improvements are very good and should be maintained, regardless of the COVID-19 situation.

- The opinion that smart learning technology facilitates the way of mastering the material is an attitude agreed by $64 \%$ of the students and $20 \%$ were neutral, as opposed to only $16 \%$ with a negative perception.

- Students point out the benefits of using an interactive $\mathrm{C}++$ book in the following ways: $46 \%$ as a useful inventive form of work, regardless of the COVID-19 situation; 44\% stated that the benefits are most prominent in COVID-19 situation; $26 \%$ stated it as resource replenishment; and $34 \%$ for downloading the code for offline practice. (Students on this issue can make multiple choices.)

- Asked about the overall evaluation from a personal aspect, on the transition to full online activities, $44 \%$ did not see significant changes, $38 \%$ see improvements, while for $16 \%$ of the students the teaching process is more difficult.

\subsection{Functional decomposition of smart learning technology for computer programming}

The developed technology for smart learning is based on customized open-source solutions, which are functionally embedded in the already existing s-learning environment. According to Figure 2 , there are two main ways to use it, marked as activity lines 1 and 2.

- Line 1: Accessing smart learning technology; selecting a working example; compiling and executing without any changes, directly on the page; displaying results on screen (compiler console) optionally; downloading of working example for future educational needs and offline use.

- Line 2: Accessing smart learning technology; selecting a working example; option to change a selected example, by changing the code and input variables, by selecting Interactive mode; results on screen (compiler console) optionally; downloading of the selected and customized example for future educational needs and offline use.

Smart learning technology is conceived as an interactive book with $\mathrm{C}++$ ready to compile and execute teaching examples. There is scalability and adjustment in the way it is used, according to the needs of the user. The 'smartness' of this technology consists of the following functional features:

- A working example with a code can be accessed by multiple students at the same time, and each student can make individual changes to the code example in real time.

- Individual changes to the code made by students do not affect the initial working example. Despite the individual changes at work, the example remains in its original form given by the creator (professor), for further use.

- Custom settings allow online editing, compiling and execution without the need for an account and system login. 
- The integration of the smart learning technology with the s-learning system enables the transition to personal work mode and the possibility to log in to a previously generated personal account on jdoodle.

The described smart learning technology is completely based on open-source solutions, and programming activities for embedding and customizing existing resources. The main challenge was to connect the various open-source platforms with the new smart learning technology, in a way to become an integral smart part of the s- learning environment.

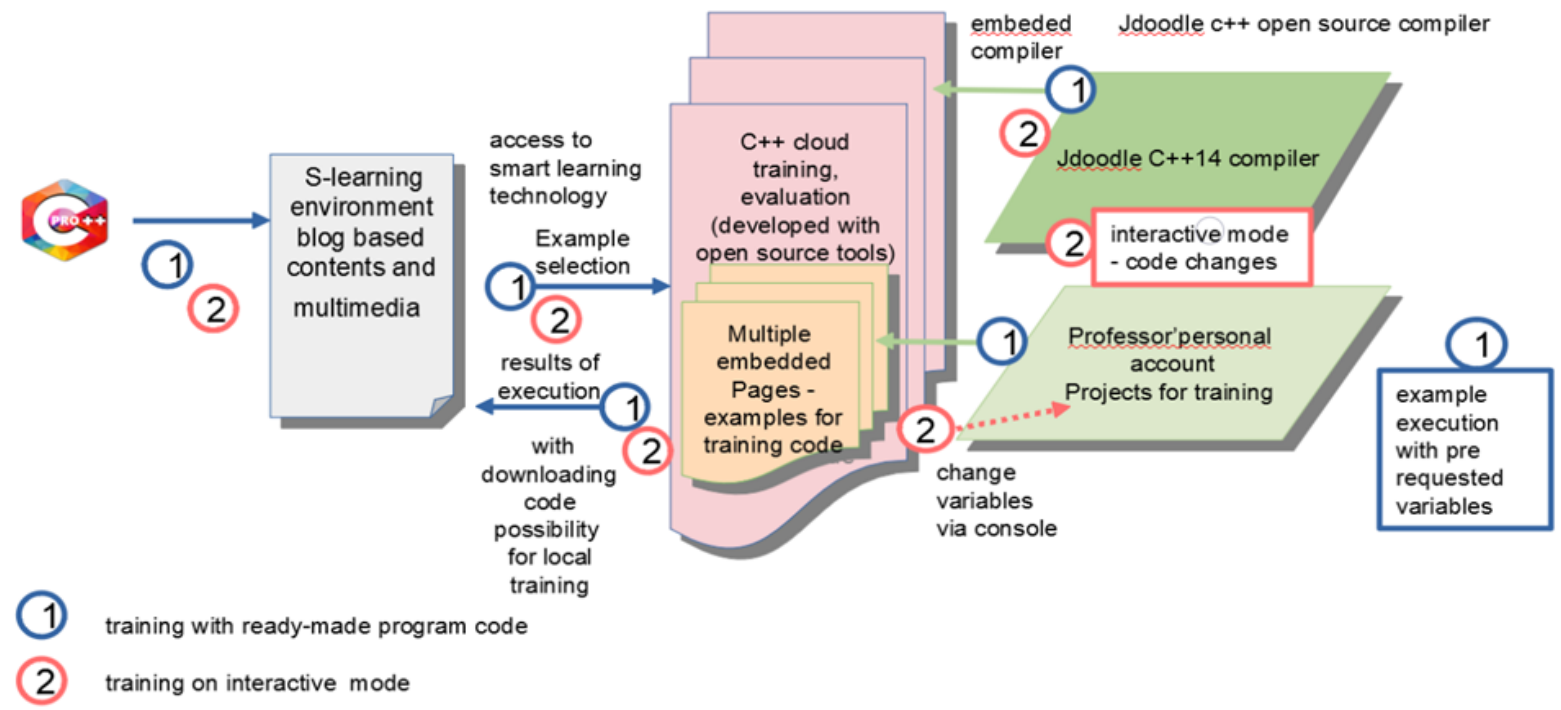

Figure 2: Smart learning technology - functional decomposition

\subsection{Demonstration of 'smart learning technology' use in computer programming}

Executive Screens demonstrating the operation options of smart learning technology are shown in Figure 3. For traceability, activities will be explained by pointing to the numbers that mark the executive screens, (as parts of whole image).

- The main page, where a pre-existing learning environment as a whole is presented, contains the built-in link (1) of smart learning technology.

- The next window (2) gives the code from the called example. Depending on the needs, it is executed directly, or in interactive mode, input variables are entered.

- As mentioned earlier, there is an option for local download, (3) through options for saving locally or printing.

- The interactive mode offers the option to change the code, and different types of errors are possible (4), which need to be removed. In this case, there are instructions on the screen to follow.

- When the modified code is ready for use, in interactive mode, the values of the variables can be entered during console execution (5) or before execution, with Stdin input option (6).

- Usually, if the working example is just executed without modifications, it is working on the basic screen of smart learning technology. 
Markoska, R. (2021). Smart learning technology for computer programming based on research related to COVID-19. Global Journal of Computer Sciences: Theory and Research. 11(2), 88-99. https://doi.org/10.18844/gjcs.v11i2.5380

- In case of changes, it is configured to switch to the jdoodle service (7) without the need to create an account.

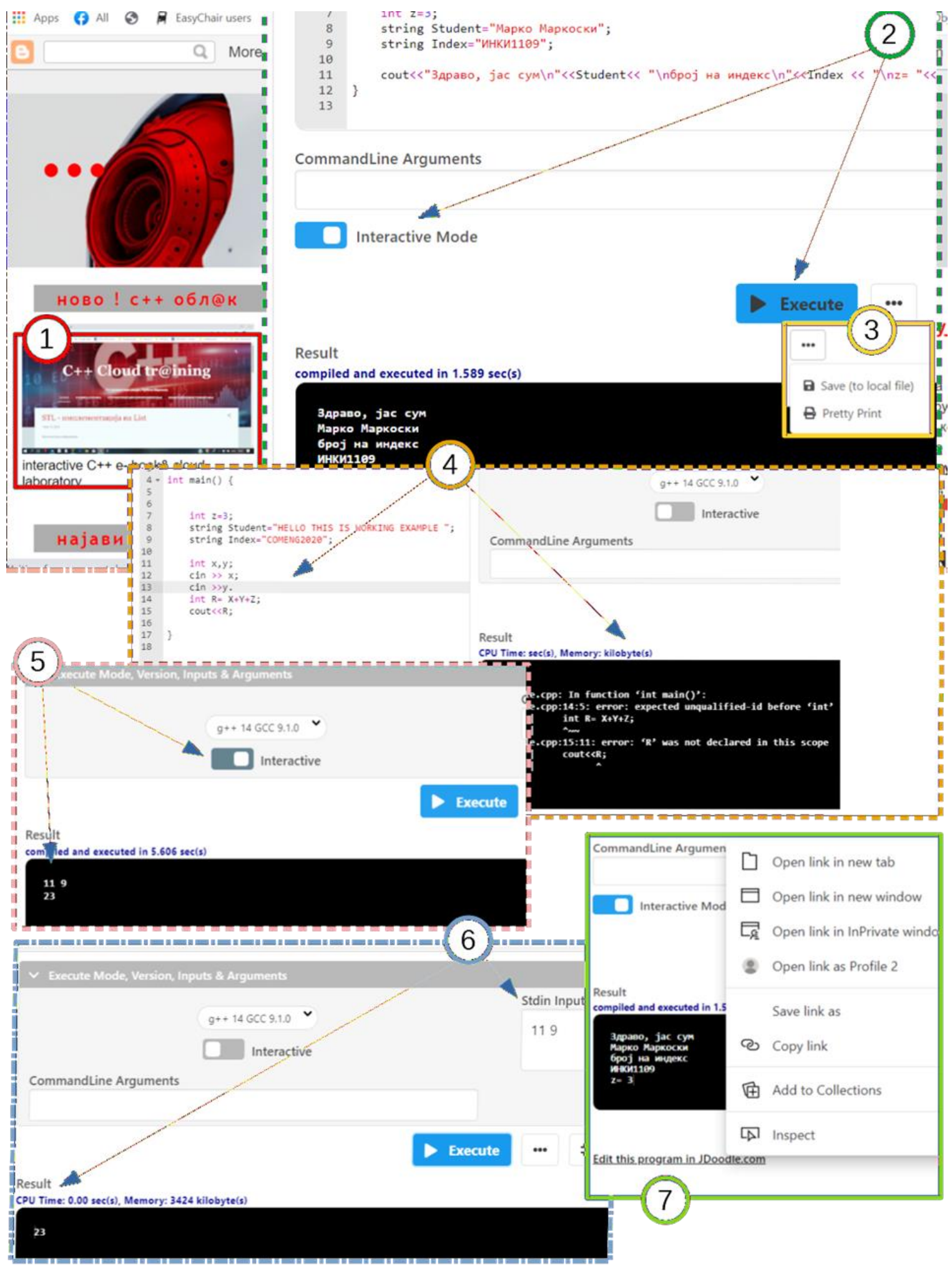


Figure 3. Practical demonstration of the smart learning technology options

\section{Discussion}

The multifaceted analysis shows that, as a generation that spends a lot of time online and in front of the computer [1], the students are well adapted to change and embrace new technologies for smart learning. Statistics show that the use of new technologies in computer programming contributes to better mastering of the material.

Speaking of smart learning technologies, it can be noticed that they provide the signpost for how future learning digital environments and ecosystems should be shaped. Their widespread use is an incentive to standardise their development and application by a competent ISO committee. Standardisation work involves conceptual, technical and social activities. A key goal of researchers is to optimise the use of smart learning technologies, thereby ensuring improvement of learning ecosystems through a continuous repetitive loop of innovation $[8,10]$. The activities to achieve that goal are multifaceted and interdependent. They are mostly influenced by the openness of the educational process, and the ways and levels of implementation of technological innovations. Regarding the use of new technologies, there are new participants who enable the rediscovery of new ways in the formal learning processes and development of new educational paradigms in the informal learning processes.

Regarding the providers of new technologies, there are two main categories recognized: new participants, who enable the rediscovery of new ways in the formal learning processes and development of new educational paradigms in the informal learning processes, and existing providers, who ensure improvements of formal learning processes and offer the supplementing of informal learning processes [10]. Hybrid solutions are always allowed when using, which are a compilation of the most suitable features of the two basic categories. According to the given framework classification, the smart learning technology presented in this paper belongs to the categories of formal learning and existing provider, which means it improves the existing pre-existing digital learning ecosystem. But it is also a new paradigm, which has independent functionalities that are supplements to the pre-existing ecosystem. At this stage, the results of the student questionnaire, together with future questionnaires from the following years, can be used for possible future improvement or for the need to reinvent (according to the previous description) the smart learning technology. The following is a detailed description of the various aspects of the development, application and integration of smart learning technology, which is the subject of this paper. In the context of integration with the pre-existing smart learning ecosystem, the new smart learning technology will be clarified from two aspects: through functional decomposition and through a practical demonstration of the upgraded options it offers.

\section{Conclusion}

At the conceptual level, the presented smart learning technology has the potential for wide adaptation. It enables its application in many educational areas, although it is best suited for technical areas where ICT solutions are used. Regardless of the COVID-19 situation, also the intense social changes in the second decade of the 21st century is correlated with the changes in the ICT environment. Even more, modern education relies on the use of ICT solutions, following the habits of 
young people to use computers and the Internet. The imposed situation with the new reality conditioned by COVID-19. requires further intensive digitisation of social living, which must be supported and enabled by improving existing ICT solutions and developing new ones. According to the theories and practices of modern digital ecosystems, neither the largest nor the most equipped, but the most adapted to these new conditions, are progressing. Especially, the smart learning technologies development and use in this COVID-19 situation is an imperative of success and 'surviving' because the highlighted great possibility of smart customisation and adaptation.

The term 'smart' can be considered as a series of choices and activities that are preceded by thoughtful analysis and backed-up by concrete results that achieve set goals. According to the given analyses, the set goals, and the obtained results of the smart learning technology, described in this paper, have a factor of pronounced adjustment, compatibility with the learning conditions and correlation in the educational offers. It thus finds its place globally within a modern and open digital learning ecosystem, with opportunities for wider application than the s-learning environment for which it was developed. As Einstein says, elegance is for tailoring salons, unlike science, where the same items are often considered and described from different points of view formally, repeating that in the descriptions of smart learning technology, certain functionalities were described and represented by different points of view.

The term smart is not a privilege, but an obligation and aspiration for constant smart adjustments, in accordance with the changes in the educational environment. The situation resulting from COVID19 shifted people's habits in the field of social activity and interaction, for leisure activities, education, and work. According to the reactions of the participants in the educational process, both students and teachers, there is a determination and attitude that smart learning technologies bring unconditional benefits, despite some small restrictions.

\section{References}

1. Green, H., Facer, K., Rudd, T., Dillon, P., Humphreys, P. (2005). Futurelab: Personalisation and Digital Technologies. Hal-00190337. Retrieved October 3, 2020, from https://telearn.archives-ouvertes.fr/hal$\underline{00190337}$

2. Arome, G. (2016). Distance learning: sustaining support services for online learners. In G. Chamblee \& L. Langub (Eds.), Proceedings of society for information technology \& teacher education international conference (pp. 155-158). Savannah, GA: Association for the Advancement of Computing in Education (AACE). Retrieved October 7, 2020, from https://www.learntechlib.org/primary/p/171664/

3. Kim, T., Cho, J., B. \& Lee, B. (2013). Evolution to smart learning in public education: a case study of Korean public education (pp. 170-178). 1st Open and Social Technologies for Networked Learning (OST), Jul 2012, Tallinn, Estonia. doi: 10.1007/978-3-642-37285-8_18, hal-01349415

4. Spector, J.M. (2016b). The potential of smart technologies for lainin and instruction. International Journal of Smart Technology and Learning, 1, 21. doi:10.1504/IJSMARTTL.2016.078163

5. Uskov V. L., Bakken J. P. \& Pandey A. (2015). The Ontology of Next Generalini Smart Classrooms. In L. V. Uskov, R. Howlett \& L. Jain (Eds.), Smart education and smart e-learning. Smart innovation, systems and technologies (vol. 41). Cham, The Netherlands: Springer. Doi:10.1007/978-3-319-19875-0_1 
6. Ilkyu, H. \& Chonggun, K. (2014). The research trends and the effectiveness of smart learning. International Journal of Distributed Sensor Networks, 2014, Article ID 537346, 9. doi:10.1155/2014/537346

7. Spector, J.M. (2016a). Smart learning environments: concepts and issues. In G. Chamblee \& L. Langub (Eds.), Proceedings of society for information technology \& teacher education international conference (pp. 2728-2737). Savannah, GA: Association for the Advancement of Computing in Education (AACE). Retrieved October 8, 2020, from https://www.learntechlib.org/primary/p/172078

8. Kuppusamy, P. (2020). Emerging technologies to smart education. International Journal of Emerging Trends \& Technology in Computer Science, 68, 5-16. doi:10.14445/22312803/IJCTT-V68I2P102

9. Zhu, Z., Yu, M. \& Riezebos, P. (2016). A research framework of smart education. Smart Learning Environments, 3, 4. doi:10.1186/s40561-016-0026-2

10. Hoel, T. \& Mason, J. (2018). Standards to smart education- towards a development framework, Smart Learning Environments, 5, Article number: 3. doi:10.1186/s40561-018-0052-3 